\title{
OBTENÇÃO DE EXTRATOS NATURAIS A PARTIR DE ANTOCIANINAS PRESENTES EM FOLHAS, FRUTAS E FLORES NA FABRICAÇÃO DE PAPEL INDICADOR DE $\mathrm{pH}$
}

\section{SHEMINY FREITAS_ZAHREDDINE ${ }^{1}$; MARIA DE FÁTIMA DE MENDES PAIXÃ ${ }^{2}$; EMILLY ADORNO DE LIMA VASCONCELOS ${ }^{3}$.}

1.Bolsista Pibic/Fapesb, Graduanda em Engenharia de Alimentos, Universidade Estadual de Feira de Santana, e-mail: sheminyfsaa@hotmail.com

2.Orientadora, Departamento de Ciências Exatas, Universidade Estadual de Feira de Santana, e-mail: fpaixão100@gmail.com

3.Participante do projeto, Graduanda em Engenharia de Alimentos, Universidade Estadual de Feira de Santana, email: millyadorno95@gmail.com

PALAVRAS-CHAVE: Antocianina; indicador; extrato.

\section{INTRODUÇÃO}

Os indicadores ácido-base ou indicadores de $\mathrm{pH}$ são substâncias orgânicas fracamente ácidas (indicadores ácidos) ou fracamente básicas (indicadores básicos) que apresentam cores diferentes para suas formas protonadas e desprotonadas; ou seja, mudam de cor em função do pH (TERCI E ROSSI, 2002). Diversas espécies de plantas, flores e frutas possuem substâncias coloridas em sua seiva que mudam de cor conforme o pH do meio em que estão inseridas, sugerindo que tais espécies podem agir como indicadores ácido-base. Uma alternativa para ensinar a técnica de titulação em aulas práticas é a utilização de corantes naturais que possuem a capacidade de mudar de cor quando varia o pH (CUCHINSKI, CAETANO E DRAGUNSKI, 2010).

Vários indicadores naturais ácido-base extraídos de partes das plantas já foram descritos na literatura como indicadores de $\mathrm{pH}$, dentre os quais o mais enfatizado é o extrato do repolho roxo. Esta mudança de cor dos extratos obtidos de plantas pode estar relacionada à presença de antocianinas que exibem coloração diferente dependendo do meio em que estão inseridas, sugerindo que esses extratos podem ser utilizados como indicadores naturais ácido-base (UCHÔA et al., 2016).

Atualmente, sabe-se que as antocianinas (pigmentos da classe dos flavonóides) são responsáveis pelas cores azul, violeta, vermelho e rosa de diversas flores e frutas (TERCI E ROSSI, 2002). A palavra antocianina é de origem grega (anthos, uma flor, e kyanos, azul escuro). Depois da clorofila, o grupo mais importante de pigmentos de origem vegetal é o das antocianinas, que compõem o maior grupo de pigmentos solúveis em meio aquoso do reino vegetal e são encontradas em maior quantidade nos grupos dos vegetais angiospermas (UCHÔA et al., 2016).

As variadas cores exibidas pelos vegetais que contêm antocianinas dependem da influência de diversos fatores, como a presença de outros pigmentos, de quelatos com cátions metálicos e o pH do fluído da célula vegetal (TERCI E ROSSI, 2002). 
O objetivo desse trabalho foi pesquisar o uso de fontes naturais, principalmente flores, ricas em antocianinas para posterior fabricação de indicadores ácido-base, a partir da mudança de coloração que tais pigmentos apresentam em diferentes pHs.

\section{MATERIAL E MÉTODOS}

A obtenção do corante foi feita a partir da extração aquosa e a frio, por maceração com almofariz e pistilo. A proporção utilizada foi $10,00 \mathrm{~g}$ de pétala de flores para 50 $\mathrm{mL}$ de água, de acordo com o trabalho realizado por BERNARDINO et al. (s.d.). A extração alcoólica utilizou a proporção de 3:1, relação entre solvente e pétalas, conforme trabalho realizado por TERCI (2002). A reciclagem foi feita utilizando papel usado picado, dissolvido no extrato da flor, triturado em liquidificador. O papel seco foi usado para a confecção da fita indicadora de $\mathrm{pH}$. O teste da fita indicadora de $\mathrm{pH}$ feito por imersão ou gotejamento nas soluções ácidas e básicas.

\section{RESULTADOS E/OU DISCUSSÃO}

Com o presente trabalho, foi possível observar a dificuldade em realizar a reciclagem de papel umedecida com o extrato, devido à proporção extrato $\backslash$ papel usada. A quantidade de extrato para o montante de papel era insuficiente para que houvesse uma boa trituração no liquidificador e assim formar uma "polpa", característica do processo, que nos permitisse obter, após secagem um papel liso (apresentava-se rugoso e com partes ainda inteiras do papel original). Além disso, outro problema enfrentado residia na falta de liga na "polpa", insuficiente para que quando fosse colocada na tela ficasse unida. Usou-se, em alguns casos, uma pequena quantidade de cola para observar se esta proporcionava melhor adesão, porém sua adição propiciou mudança de coloração na folha de papel.

Outra dificuldade encontrada foi a retirada do papel da tela, pelo fato deste ficar seguro no molde e após desenformar, não ficar com a forma característica de uma folha de papel, como mostrado na Figura 1.

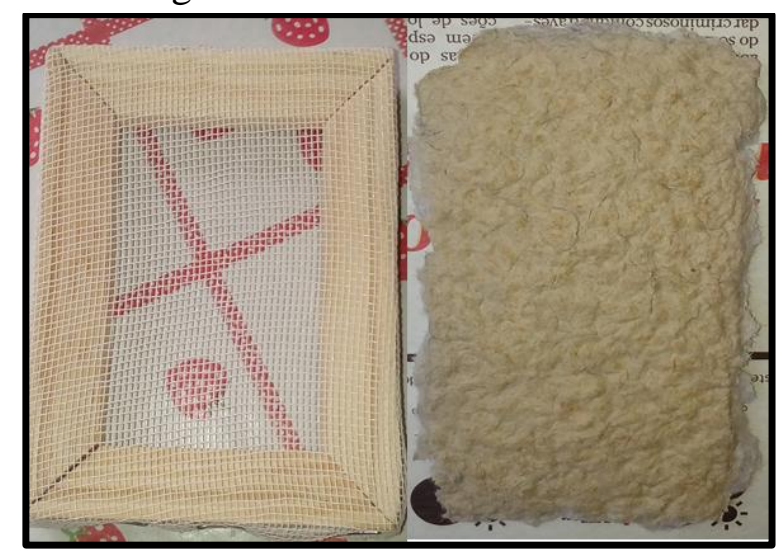

Figura 1. Á esquerda, tela adaptada; à direita, papel reciclável de Plumbago auriculata com jornal. 
Ao longo da realização dos testes, outro contratempo encontrado foi identificar um papel que realmente servisse para ser usado no processo de reciclagem e que no final obtivéssemos um resultado satisfatório para a confecção da fita indicadora de $\mathrm{pH}$. Foram testados jornal, folha de ofício A4 e papel de filtro. Inicialmente, foi utilizado o jornal, com maior flexibilidade e baixo custo. Porém, a tinta da escrita do jornal interferiu na visualização da mudança de coloração em soluções ácidas e básicas. Mesmo assim, de todos os papeis utilizados, o jornal foi o que apresentou a melhor formação da "polpa" característica do processo, com melhor trituração no liquidificador, como pode ser observado abaixo na Figura 2.

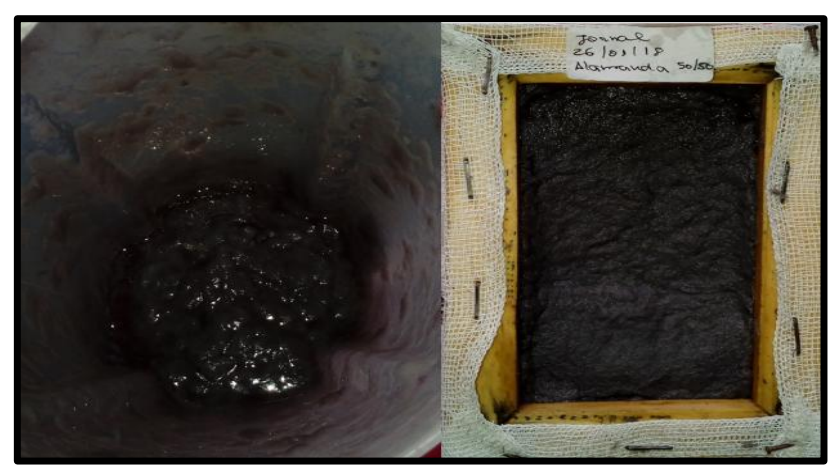

Figura 2. Obtenção do papel reciclável com jornal e extrato de Alamanda blanchetti.

Logo após os testes realizados com jornal, utilizou-se a folha de ofício A4 branca, porém os resultados obtidos não foram satisfatórios, já que esta apresenta menor flexibilidade em relação ao jornal e, consequentemente, maior dificuldade para ser triturada. Isso impossibilitava a formação da pasta, permitindo que ainda houvesse pedaços grandes de papel, o que interferia na formação e espessura da folha reciclada. Por último utilizou-se o papel de filtro, que comparativamente a folha de ofício A4, também apresentou dificuldade em ser triturada e na formação da liga na hora de colocar na tela. A Figura 3 mostra um processo de obtenção de papel reciclado através do papel de filtro de laboratório.

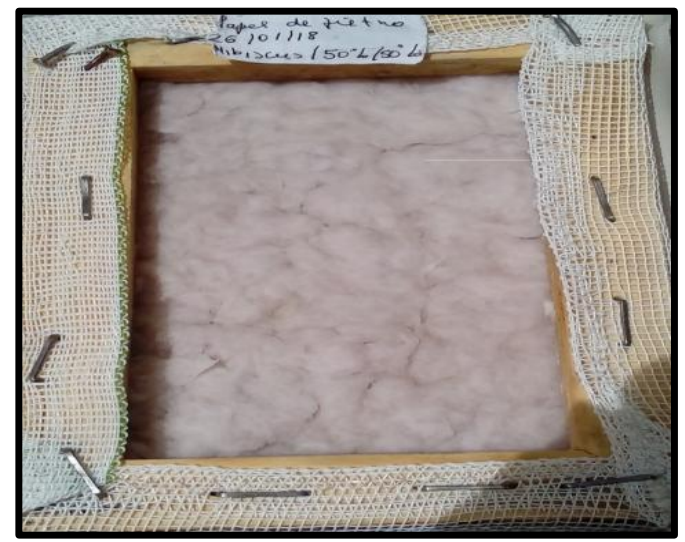

Figura 3. Papel reciclável a partir de papel de filtro utilizando extrato de Hibiscus. 
No processo de secagem do papel na tela, houve mudança de coloração na maioria dos casos, presente na superfície que ficou exposta ao sol, assim como o fato de possivelmente o excesso de sol ter deixado o papel quebradiço, como demonstrado na Figura 4.

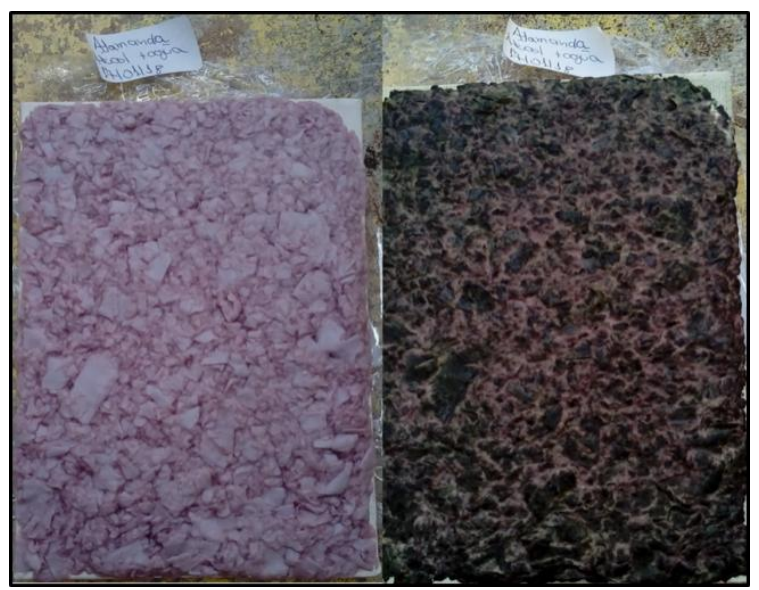

Figura 4. Mudança de coloração da Alamanda blanchetti após algumas horas.

Foi realizado também teste de coloração do extrato em solução de ácido clorídrico e hidróxido de sódio, permitindo visualizar nos dois casos a mudança de coloração, sendo que no primeiro a coloração ficava rósea e no segundo, verde. As flores utilizadas foram a Hibiscus, Alamanda blanchetti e a Plumbago auriculata. Foram realizados também os testes de coloração do papel reciclado com soluções do cotidiano: A solução ácida usada foi o vinagre e a solução básica usada foi o detergente. O meio neutro usado foi a água. Percebeu-se que:

- Alamanda blanchetti com jornal e extrato 50\%/50\%: em solução ácida assim como na básica não houve mudança de coloração pela dificuldade encontrada com a utilização do jornal;

- Alamandablanchetti com papel de filtro, acrescida de cola, e extrato 50\%/50\%: em nenhuma das soluções houve mudança de coloração;

- Alamandablanchetti com folha de ofício e extrato alcoólico: no vinagre, houve um pouco de perda da cor verde que estava no papel;

- Hibiscus com papel de filtro e extrato 50\%/50\%: houve mudança de coloração nas soluções: no vinagre ficou rósea e no detergente ficou esverdeado;

- Hibiscus com folha de ofício e extrato $80 \%$ alcoólico/20\% aquoso: houve também mudança de coloração. No vinagre o papel ficou rosado e no detergente ficou levemente verde;

- Hibiscus com folha de ofício, acrescida de cola, e extrato alcoólico: houve mudança de coloração apenas no vinagre, onde o papel ficou rosa;

- Hibiscus com jornal e extrato 50\%/50\%: houve mudança de coloração do papel nas soluções, ficando levemente e superficialmente rosa com o vinagre e levemente verde nas extremidades com o detergente; 
- Plumbago auriculata com jornal e extrato aquoso: não houve mudança de coloração em nenhuma das soluções.

Com isso, foi possível observar que as flores apresentaram diferentes resultados para diferentes meios em diferentes situações e que, no geral, a que apresentou melhor resultado entre elas quanto à coloração foi a Hibiscus, o que pode ser visualizado na Figura 5 abaixo. Não foram realizados testes de variação de cor com a Plumbago auriculata utilizando papel de filtro.

O processo de reciclagem de papel é possível de ser usado, necessitando, entretanto, adequar a quantidade a ser usada de extrato com o processo de reciclagem supracitado, para que desta forma seja possível obter a fita indicadora de $\mathrm{pH}$. Além disso, os extratos de antocianinas podem ser usados conjuntamente com o papel reciclado para compor a fita anteriormente citada. Embora nossos resultados não tenham nos permitido alcançar todos os nossos objetivos, nos indicou o caminho a seguir para alcançá-los.

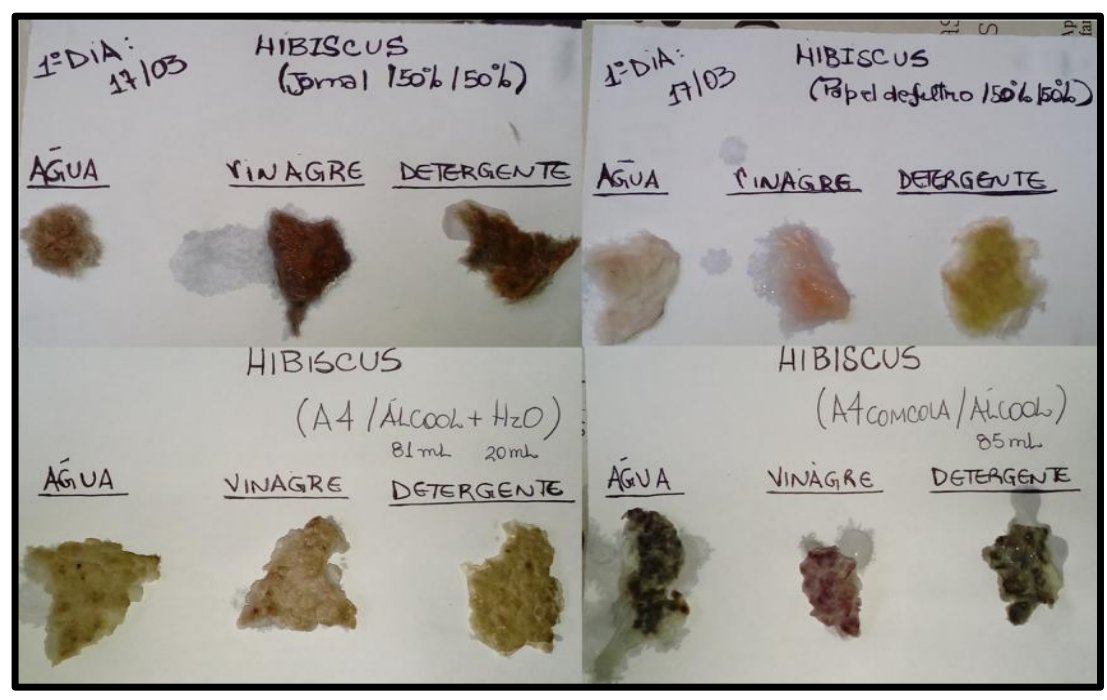

Figura 5. Mudança de coloração dos papeis com

Hibiscus em diferentes meios.

\section{CONSIDERAÇÕES FINAIS}

O trabalho nos permitiu formar noções iniciais acerca do processo de reciclagem de papel, assim como do uso de antocianinas como indicadores de $\mathrm{pH}$. Além disso, foi possível a obtenção de um conhecimento mais aprofundado no que diz respeito à importância da reciclagem de papel, tanto socialmente quanto ambientalmente. Com os estudos realizados para a realização desta pesquisa, cada parte da aprendizagem e das experiências vividas foi cada vez mais se enraizando e trazendo a tona à curiosidade e a vontade de levar a diante os resultados obtidos, com o intuito de melhorá-los e aperfeiçoá-los. Ademais, é de fundamental importância à realização de mais testes, tanto referente ao papel, assim como para a proporção papel e extrato, de forma a obter um papel reciclado de qualidade para aplicação como fita indicadora de $\mathrm{pH}$. Com isso, a 
pesquisa realizada estimulou nosso interesse pela continuidade do trabalho, bem como para ampliar meus conhecimentos sobre reciclagem de materiais e sobre as antocininas.

\section{REFERÊNCIAS}

TERCI, D.B.L.; ROSSI, A.V. Indicadores naturais de pH: usar papel ou solução? Química Nova, v.25, n.4, p.684-688, 2002. Disponível em: <http://quimicanova.sbq.org.br/imagebank/pdf/Vol25No4_684_25.pdf>. Acesso em: 06 de Agosto de 2018.

CUCHINSKI, A.S.; CAETANO, J.; DRAGUNSKI, D.C. Extração do corante da beterraba (Beta vulgaris) para utilização como indicador ácido-base. Eclética Química, $\quad$ v.35, n.4, 2010. Disponível em: <http://www.scielo.br/pdf/eq/v35n4/02.pdf>.Acesso em: 06 de Agosto de 2018.

UCHÔA, V.T.; FILHO, R.S.M.C.; LIMA, A.M.M.; ASSIS, J.B. Utilização de plantas ornamentais como novos indicadores naturais ácido-base no ensino de química. Universidade Estadual do Piauí, v.2, 2016. 